
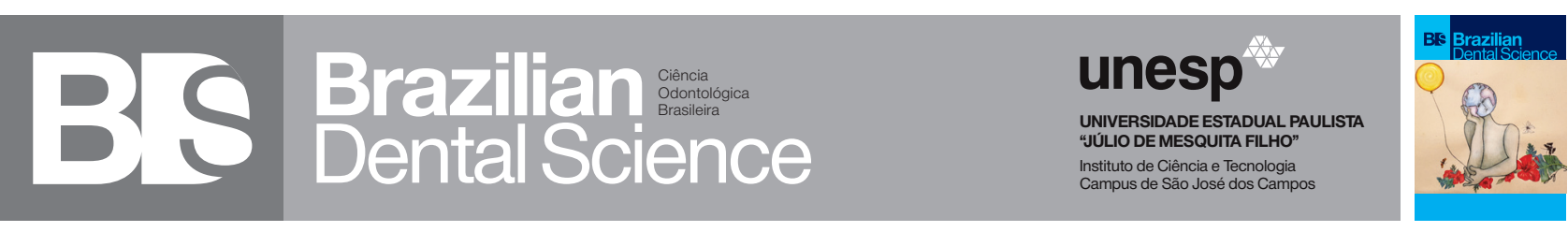

\title{
Diagnostics of non-carious lesions of dental hard tissues with the methods of optical spectroscopy and radiography
}

\author{
Diagnóstico de lesões não cariosas de tecidos duros dentais com os métodos de espectroscopia óptica e radiografia \\ Iraida SARYCHEVA ${ }^{1}$, Oleg YANUSHEVICH ${ }^{2}$, Dmitriy MINAKOV ${ }^{3}$ \\ 1 - Institute of Additional Professional Education (Dentistry) - Voronezh State Medical University - Voronezh - Russia. \\ 2 - President of Moscow State University of Medicine and Dentistry - Moscow - Russia. \\ 3 - Basic Department of Additive Technologies under the Faculty of Physics - Voronezh State University - Voronezh - Russia.
}

\begin{abstract}
Objective: This work aims to use new spectroscopic and radiographic methods to study the dental hard tissue erosion and abfraction, as these lesions are actually quite difficult to be diagnosed in clinical practice. Material and Methods: This in vivo study was conducted on 60 patients with early erosion and 60 patients with abfraction at the cervical area by means of laser-induced fluorescence (LIF) and multilayer spiral computed tomography (MSCT). Results: In comparative dental hard tissues studies LIF spectra from intact and affected areas, it was noted multidirectional fluorescence intensity dependence between areas affected by abfraction and intact areas. MSCT technique allowed assessing the degree of damaged areas, especially at deeper stages. Conclusion: Although LIF and MSCT methods presented limitations, it was shown their effectiveness in the diagnosis of abfraction and erosion by detecting changes in the morphological structure as well as in the chemical and mineral composition of affected dental hard tissues. So LIF and MSCT methods can be successfully used in order to develop new medical devices which will provide most accurate clinical diagnose of different stages of dental erosion and abfraction.
\end{abstract}

\section{KEYWORDS}

Fluorescence spectroscopy; Spiral computed tomography; Tooth demineralization;Tooth erosion.

\section{RESUIMO}

Objetivo: Este trabalho tem como objetivo utilizar novos métodos espectroscópicos e radiográficos para estudar a erosão e a abração do tecido duro dentário, pois essas lesões são realmente bastante difíceis de serem diagnosticadas na prática clínica. Material e Métodos: Este estudo in vivo foi realizado em 120 pacientes com erosão e abração precoces na área cervical por meio de fluorescência induzida por laser (LIF) e tomografia computadorizada em espiral multicamada (MSCT). Resultados: Em estudos comparativos espectros de LIF, de tecidos duros dentais intactos e afetados, observouse dependência da intensidade da fluorescência multidirecional entre as áreas afetadas pela abração e as áreas intactas. A técnica MSCT permitiu avaliar o grau de áreas danificadas, principalmente em estágios mais profundos. Conclusão: Embora os métodos LIF e MSCT tenham apresentado limitações, foi demonstrada sua eficácia no diagnóstico de abração e erosão, detectando alterações na estrutura morfológica e na composição química e mineral dos tecidos duros afetados. Portanto, os métodos LIF e MSCT podem ser utilizados com sucesso, a fim de desenvolver novos dispositivos médicos que fornecerão um diagnóstico clínico mais preciso de diferentes estágios de erosão e abração dentária.

\section{PALAVRAS-CHAVE}

Espectroscopia de fluorescência; Tomografia computadorizada em espiral; Desmineralização dentária; Erosão dentária. 


\section{INTRODUCTION}

$\mathrm{O}$ ne of the main problems of modern dentistry is the diagnosis and treatment of non-carious lesions of dental hard tissues. This kind of pathology is the most widely common, next to caries, which often leads to progressive loss of dental enamel and dentin. This hard tissue loss may lead to the decrease of chewing function and even cosmetic defects [1-3]. An early non-carious lesion, which can be clinically detected quite often, is the abfraction or wedge-shaped defect. Itpresents a certain similarity with cervical caries and erosion and is also taken into account in clinical dentistry in the diagnosis of enamel hypoplasia and dental fluorosis. Another extremely common non-carious lesion is tooth erosion. It should be noted that initial manifestations of the non-carious lesions are quite similar in terms of surface roughness and slight loss of hard tissues. Similar symptoms of the clinical progression, especially during the initial period,make difficult the diagnosis and the choice of therapeutic and preventive measures [4-11].

Modern dentistry has a small set of methods and tools for the abfraction clinical diagnosis. The standard procedure is still occupied by historically established traditional clinical methods of investigation: examination, history taking, thermal testing, vital staining of teeth, etc. Nevertheless, the use of these methods does not guarantee accurate abfraction diagnosis, especially at the initial stages. Methods of dental erosion evaluation have already been established [12-16], among them: contact and contactless profilometry, registration of enamel hardness profile, microradiography, optical coherent tomography, laser-induced fluorescence, reflection and scattering spectroscopy, scanning electron microscopy, energy-dispersive X-ray spectroscopy and various chemical methods of analysis of calcium ions and phosphates. Although, important for understanding the various aspects of erosion, special attention should be paid to the methods from which medical devices are developed, aiming early diagnosis of erosion in vivo. Among them, the present study contemplates the laser-induced fluorescence (LIF).

The method of luminescence spectroscopy has been successfully applied in medical fields, such as gynecology, ophthalmology, oncology and dentistry [4-11]. Over the past hundred years, many studies of teeth fluorescence have been carried out, and the obtained results suggest a diagnostic tool for the carious diseases [811]. Recent achievements in X-ray computed tomography, associated primarily with high spatial and temporal resolution, allow considering this method a very promising one for the abfraction diagnosis.

This work aims to study the possibility of clinical diagnosis and differentiation of the various stages of the abfraction with the method of LIF and multilayer spiral computed tomography (MSCT).

\section{MATERIAL AND METHODS}

The study was conducted in vivo on 60 patients having abfraction in the cervical area and 60 patients with early erosion, according to preliminary clinical studies. All procedures performed were approved by the institutional Ethics in Research Committee and in accordance with the 1964 Helsinki declaration and its later amendments. The study was independently reviewed and approved by the Ethical Board of Voronezh State Medical University named after N.N.Burdenko on October 30, 2018 (Protocol №2). Informed consent was obtained from each patient.

The stages of non-carious processes were defined in compliance with the topographic classification of abfraction: initial, superficial, middle and deep. Fluorescence spectra were recorded with the use of a patented device designed on the basis of fiber-optic spectrometer USB4000-VIS-NIR (Ocean Optics, Orlando, FL, USA), connected to the computer [17]. Probing area of the teeth was determined by the area of the waveguide and was equal to $0.28 \mathrm{~mm}^{2}$. A laser diode emitting at the wavelength of $445 \mathrm{~nm}$ was used as a source of fluorescence excitation. Radiation power density was not more than 20 $\mathrm{mW} / \mathrm{cm}^{2}$. Measurements were performed inside a shaded room with no sources of scattered light. Fluorescence spectra of tooth enamel were obtained from cervical areas of intact teeth and teeth affected by abfraction. No less than 10 fluorescence spectra were registered from each area of each examined tooth, and all of the spectra were averaged. In cases when there was no intact area in the affected tooth, the reference spectrum was obtained from the intact cervical area of 
an equivalent tooth. This is important because our investigations of intact teeth indicate the dependence of fluorescence spectrum both on the anatomic area of a tooth and on the tooth type in the upper and the lower jaw [18-23]. Fluorescence spectrum of the intact area of the tooth was used as an indicator of spectral changes caused by pathological processes. Before the luminescence examinations were performed, the patients had undergone the procedure of professional oral hygiene and had been recommended to use toothpaste that did not make any considerable contribution into the registered signal.

The MSCT method was also used for detecting abfraction in vivo. The studies were performed with the device Philips Brilliance ICT 64 (Philips Medical Systems, Miramar, FL, USA) with a slice thickness of $0.55 \mathrm{~mm}$ in the axial plane. The plane of scanning was perpendicular to the occlusal plane. The level of visualization was formed in the area between the mental protuberance of the lower jaw and the hard palate with the capture of the alveolar openings of the maxillary sinuses. For measuring the thickness of enamel, a program OSIRIX, version 5-1.6, was applied, which allowed post-processing treatment (multiplanar reformations) of images, when the planes were aligned with the axis of the tooth and perpendicular to the occlusal plane.

\section{RESULTS}

Figure 1a represents fluorescence spectra of intact enamel in different anatomic areas and of enamel affected by superficial abfraction, averaged over all of the patients. Figure $1 \mathrm{~b}$ represents the ratio of integral fluorescence intensity of enamel affected by abfraction to the fluorescence intensity of intact enamel in the cervical area that depends on different developmental stages of this pathology.

Figures $1 \mathrm{a}$ and $1 \mathrm{~b}$ show that under excitation with irradiation at the wavelength of $445 \mathrm{~nm}$ fluorescence spectra of intact and affected enamel differ considerably in their intensity and are characterized by multidirectional dependence. For example, at the superficial stage of abfraction development, fluorescence intensity of affected enamel is more than 30\% higher than that of intact one, and at the middle and deep stages, fluorescence intensity of affected enamel is, on the contrary, lower (in case of the deep stage, even by more than $40 \%$ ). That is why, as can be seen in Figure 1b, the ratio of fluorescence intensity of affected enamel to that of intact enamel decreases from the initial developmental stage to the deep one as the difference between these intensities lessens.

In Figure 1a it can also be seen that fluorescence spectrum of intact enamel in different anatomic areas as well as of enamel affected by superficial abfraction represents quite a broad multicomponent band with the maximum at $526 \mathrm{~nm}$. In addition, the shape of fluorescence spectrum of affected enamel coincides with the shapes of fluorescence spectra of intact enamel for all the anatomic areas: cervical, equator and cutting edge. A similar tendency was observed for other stages of abfraction development.

Figure 2 shows photos of canines, one of which is intact (on the right) and the other (on the left) is affected by deep abfraction. The photos were taken with Philips Brilliance ICT 64 using MSCT method.

As seen in Figure 2, MSCT method allows visualizing the affection of teeth by abfraction. The depth of the lesion can be estimated with the use of the image processing program of Philips Brilliance ICT 64. For example, for the deep stage of abfraction development, it was equal to 0.47 $\mathrm{mm}$.

Figure 3 represents fluorescence spectra of intact enamel in the different anatomic areas and of enamel affected by early erosion in cervical area, averaged over all of the patients.

Figure 3 shows that under excitation with irradiation at the wavelength of $445 \mathrm{~nm}$ fluorescence spectra of intact and affected enamel differ considerably in their intensity. For example, at the initial stage of erosion development, fluorescence intensity of affected enamel is significantly higher than that of the intact one (not less than by 45\%). In Figure 3 it can also be seen that fluorescence spectrum of intact enamel in different anatomic areas as well as of eroded enamel represents quite a broad multicomponent band with the maximum at $526 \mathrm{~nm}$. Besides, the shape of fluorescence spectrum of affected enamel coincides with the shapes of fluorescence spectra of intact enamel for all anatomic areas: cervical, equator and cutting edge. 

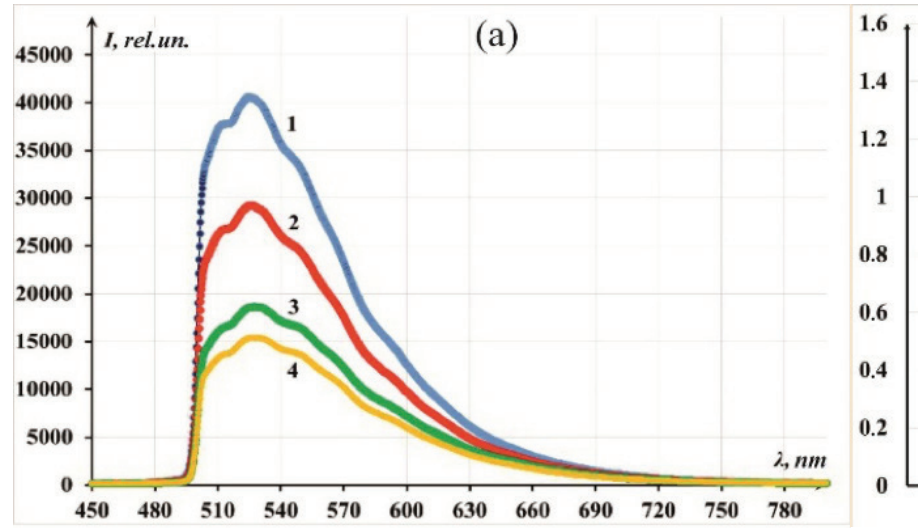

$\mathbf{I}_{\text {FL.af } / \text { LL.in. }}$

(b)

Figure 1 - a) - Fluorescence spectra of enamel: 1 - in the cervical area affected by superficial abfraction; 2 - in the intact cervical area; 3 - in the equator area; 4 - in the area of the cutting edge. b) - behavior of the integral intensity of enamel fluorescence depending on the developmental stage of abfraction. The columns represent the ratio of fluorescence intensities of enamel of teeth affected by abfraction, averaged over all the patients, to the intensity of intact enamel fluorescence in the cervical area, depending on the developmental stage of the lesion: 1 - superficial abfraction; 2 - middle abfraction; 3 - deep abfraction.

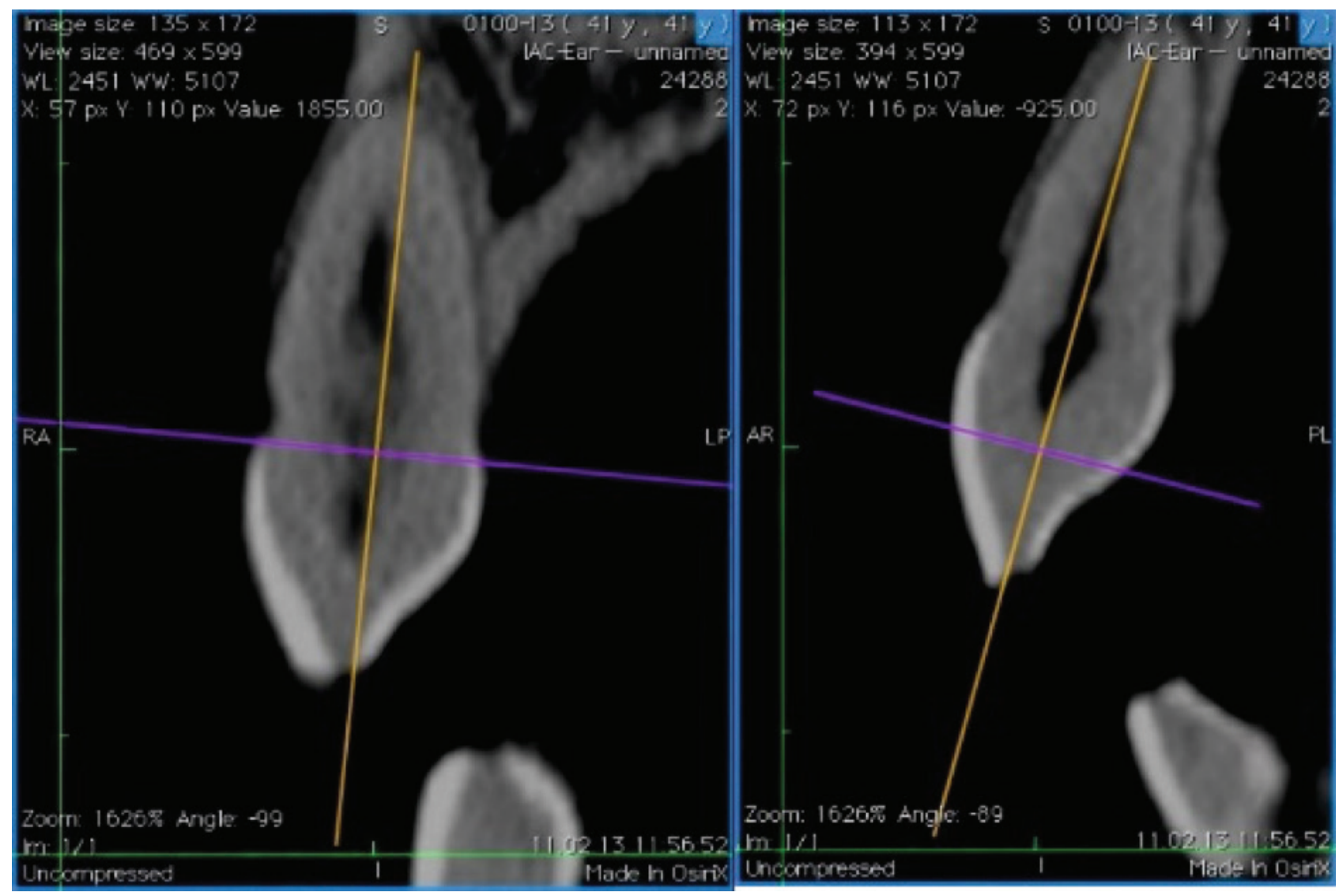

Figure 2 - Images of teeth, obtained with MSCT method: on the left - a tooth affected by a deep abfraction in the cervical area; on the right - an intact tooth. 


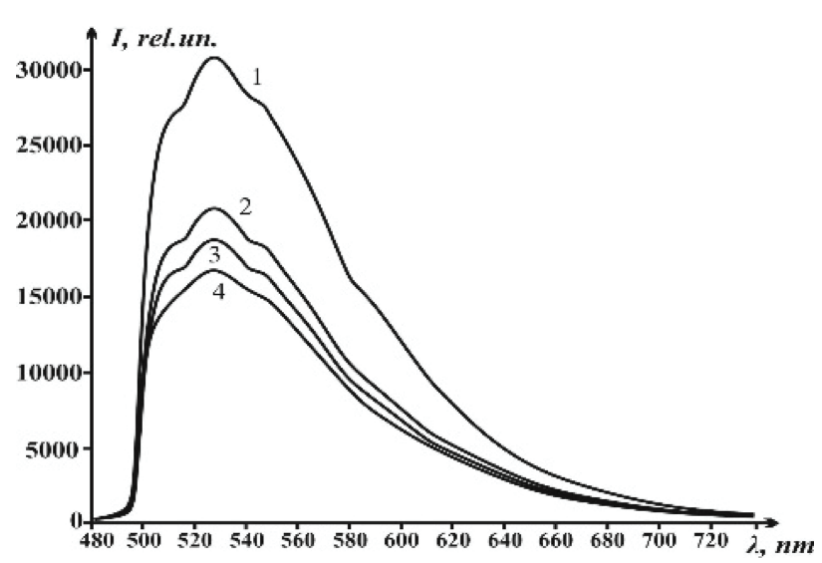

Figure 3 - Fluorescence spectra of enamel: 1 - in the cervical area affected by erosion at the initial stage; 2 - in the intact cervical area; 3 - in the area of the cutting edge; 4 - in the equator area.

\section{DISCUSSION}

To reliably diagnose abfraction and erosion with the LIF method, it is necessary to understand the fluorescence mechanism not only of the affected, but also of intact areas of dental hard tissues. Our previous investigations [18-23] have shown that fluorescence of dental hard tissues has different nature and involves the influence of organic (first of all, structural elements of collagen) and inorganic phases (impurity crystals of calcium hydroxylapatite (HAp). It has also been demonstrated that the fluorescence intensity of enamel depends on the anatomic area and on the type of the tooth. The obtained results have been connected with the influence of adjacent tissues, above all, dentin-enamel junction (DEJ) and dentin, on the fluorescence spectrum of enamel, as well as with the dependence of the optical properties of enamel on the anatomic area of the tooth. Besides, the most intense fluorescence is typical of the multi-level structure of DEJ, while enamel is characterized by the lowest fluorescence intensity. DEJ itself proved to demonstrate rather low fluorescence signal, while conchoidal layers of dentin and enamel, adjacent to DEJ, showed quite intensive fluorescence. Contribution of the fluorescent DEJ and dentin into the fluorescence spectrum of enamel is of the highest value in the cervical area, where thickness of enamel is the smallest. Therefore, fluorescence intensity of intact enamel in the cervical area is higher than in the equator area or in the area of the cutting edge due to the fluorescence of DEJ and dentin (see Figure 1a, Figure 3).

As is known, the superficial stage of abfraction development is characterized not only by enamel loss on the whole, but also by the appearance of slit-like damages of enamel up to $0.2 \mathrm{~mm}$ deep near the cement-enamel junction [24-27]. Enamel loss, as well as the presence of cracks, may be the cause of the observed increase in the fluorescence intensity of enamel in the area of superficial abfraction compared with intact enamel (see Figure $1 \mathrm{a}$ and Figure 1b). Indeed, the presence of cracks, as well as a decrease in the thickness of enamel in the lesion area, increases the penetration depth of the fluorescence exciting radiation, and thus the specific contribution of the fluorescence of DEJ and dentin into the overall spectrum of enamel fluorescence rises.

As for middle abfraction, the depth of the lesion already amounts to from 0.2 to $0.3 \mathrm{~mm}$. Deep abfraction is characterized by affection of deep dentin layers. As seen in Figure $1 b$, middle and deep stages of abfraction development, in contrast to the superficial stage, show the reverse tendency for reducing the fluorescence intensity, and at the deep stage the decrease is higher. Such spectral behavior may be due to several reasons.

Firstly, middle and deep stages are characterized by disappearance of enamel, destruction of DEJ and change in the chemical and mineral properties of dentin adjacent to the surface of the lesion [1, 2, 24-27]. Moreover, the hypermineralized layer of dentin is characterized by a decrease in the content of carbonate-substituted crystals of calcium hydroxylapatite, as well as a decrease in the cross-links of collagen and their destruction. And since the structural elements of collagen and impurity crystals of calcium hydroxylapatite, first of all, carbonate- 
substituted crystals, serve as the endogenous fluorophores of hard tissues, the observed decrease in fluorescence intensity of the areas affected by middle and deep abfraction becomes explicable.

Secondly, the optical properties of the lesion wall change. Its density increases, therefore, the depth of penetration of exciting radiation into the tooth is significantly reduced, and, consequently, the fluorescence intensity decreases.

The initial stage of abfraction development is characterized by almost invisible tissue loss, and therefore in practice it is quite hard to be diagnosed. However, since a decrease in the thickness of enamel is also typical of the initial stage, it can be expected that the affected area will also have greater fluorescence intensity, compared with intact enamel.

The early stage erosion is also characterized by an increase in fluorescence intensity of enamel, as shown in the Figure 3. At the initial stages of demineralization, light scattering increases; however, along with this, thickness of enamel decreases much more. These are two competing processes: the first one reduces and the second enhances the intensity of the exciting radiation transferred to DEJ and dentin. If the pathology is localized at the cervical area, the second process dominates, thus resulting in the enhancement of fluorescence intensity at the early stages of erosion.

As for the decrease of fluorescence intensity of the eroded enamel, observed in the work by Borisova et al. [28], it may be conditioned by the lesion localization area. Indeed, if erosion affects, for example, the area of the cutting edge enamel, fluorescence intensity can be lower than that of the intact area. This is because enamel thickness in the area of the cutting edge is considerably higher than in the cervical area. With the development of erosion, enamel is gradually destroyed, the coefficient of diffuse reflection increases in the area of fluorescence excitation and consequently, the contribution of the most intensively fluorescent tissues - DEJ and dentin - to the overall fluorescence signal decreases. Besides, it should be taken into account that under erosion, the contribution of fluorescence of endogenous fluorophores having organic (first of all, structural elements of collagen) and inorganic nature (impurity crystals of calcium HAp) in the overall fluorescence spectrum lessens. Eroded enamel is characterized by a decrease in the content of carbonate-substituted crystals of calcium hydroxylapatite as well as a considerable reconfiguration of organic phase (amide groups). Since impurity crystals of calcium hydroxylapatite and, above all, carbonatesubstituted crystals and structural elements of collagen, act as endogenous fluorophores of dental hard tissues, it seems reasonable to consider them responsible for the observed decrease of fluorescence intensity of eroded enamel in the area of the cutting edge.

At the later stages of erosion development, a decrease of fluorescence intensity should be expected, because in this case DEJ and dentin are becoming involved in this process along with their significant structural and compositional changes.

Finally, we consider the results of the abfraction diagnosis with the method of multilayer spiral computed tomography (see Figure 2). As is known, one of the fields of practical use of X-ray computed tomography in dentistry is the diagnosis of various diseases of the oral cavity, such as periodontal disease, parodontitis, non-carious and carious lesions of teeth [29, 30]. In this work we have also demonstrated the prospects of this technique for detecting abfraction. However, as our results have shown, this method has a number of significant limitations. Firstly, using this method, it is almost impossible to diagnose abfraction at the initial and superficial stages. Secondly, of course, the frequency of application of this method is limited because of a person's exposure to radiation. 
Nevertheless, this method can be very effective for the diagnosis of abfraction at the middle and deep stages of its development during the preventive examination of patients.

\section{CONCLUSION}

Results demonstrate the prospects of the LIF technique application for the diagnosis and discrimination of different stages of abfraction development as well as for the diagnosis of early erosion. Nevertheless, to develop a reliable diagnostic device capable of detecting abfraction and erosion with LIF technique, especially at the early stages, it is necessary to take into account several aspects. Firstly, it is the mechanism of fluorescence both in affected and intact areas of dental hard tissues. Specific features of morphological structure, chemical and mineral composition of hard tissues in the area of non-carious lesion development, depending on the developmental stage of the given pathology, should also be considered. Multi-spectral processing of the information requires applying contemporary mathematical methods such as neural network recognition algorithms, algorithms realizing support vector machine method and others [31-33]. The prospects of diagnosing middle and deep abfraction with MSCT method are also doubtless.

\section{REFERENCES}

1. BartlettDW, Shah P.Critical review of non-carious cervical (wear) lesions and the role of abfraction, erosion, and abrasion. J Dent Res. 2006;85(4):306-312. doi: $101177 / 154405910608500405$.

2. Levitch LC, Bader JD, Shugars DA, Heymann HO. Non-carious cervical lesions. JDent. 1994;22(4):195-207. doi:10.1016/0300-5712(94)90107-4

3. Mathias C, Ferraz LN, Nunes Leite LimaDA, Marchi GM. Treatment of noncarious lesions: diagnosis, restorative materials and techniques.Braz J Oral Scien. 2018:17:1-12. doi: 10.20396/bjos.v17i0.8652926

4. Andreoni $A$, Colasanti A, Detfino $M$, Fabbrocini G, Mastrocinque $M$, Riccio $P$, Roberti G, Santoianni P.Fluorescence imaging for diagnosis of skin diseases. J Eur Acad Dermatol Venereol.1995;5:195-7.

5. Gmitro AF,Cutruzzola FW, Stetz MS, Deckelbaum LI. Measurement depth of laser-induced tissue fluorescence with application to laser angioplasty.Appl Opt. 1988 May 1;27(9):1844-9. doi: 10.1364/A0.27.001844

6. Friesen SA, Hjortland GO, Madsen SJ, Hirschberg H, Engebraten O, Nesland JM, Peng Q.5-aminolevulinic acid-based photodynamic detection and therapy of brain tumors (review). Int J Oncol. 2002 Sep;21(3):577-82.
7. Dadvani SA, Vetshev PS, Shulutko AM,Prudkov Ml. Cholelitiasis. Moscow: Publishing house Vidar;2000.

8. Ando M, van Der Veen MH, Schemehorn BR, Stookey GK. Comparative study to quantify demineralized enamel in deciduous and permanent teeth using laser- and light-induced fluorescence techniques. Caries Res. 2001 NovDec;35(6):464-70.Doi: 10.1159/000047491.

9. Loschenov VB, Konov VI, Prohorov AM. Photodynamic therapy and fluorescence diagnostics. Laser Phys 2000; 10(6):1118-207.

10. Bachmann L, Zezell DM, de Costa Ribeiro A, Gomes L, Ito AS. Fluorescence spectroscopy of biological tissues - a review. Appl Spectrosc Rev.2006;41:575590.

11. Buchalla W. Comparative fluorescence spectroscopy shows differences innoncavitated enamel lesions. Caries Res. 2005;39:150-156.

12. Attin T.Methods for assessment of dental erosion. Monogr Oral Sci. 2006:20:152-172

13. Azzopardi A, BartlettDW, Watson TF,Smith BG. A literature review of the techniques to measure tooth wear and erosion. Eur JProsthodont Restor Dent. 2000;8:93-97.

14. Barbour ME, Rees JS. The laboratory assessment of enamel erosion: a review. JDent2004;32:591-602.Doi:10.1016/j.jdent.2004.05.001.

15. Field J, Waterhouse P,German M. Quantifying and qualifying surface changes on dental hard tissues in vitro. J Dent. 2010 Mar;38(3):182-90. doi: 10.1016/j. jdent.2010.01.002

16. Grenby TH.Lessening dental erosive potential by product modification. Eur J Oral Sci. 1996 Apr;104(2(Pt2)):221-8.

17. Sarycheva IN, Yanushevich 00, Minakov DA, Shulgin VA, Kashkarov VM. Fibre-optic device for detecting fluorescence. Russian Federation patent RF 2464549.2011

18. Sarycheva IN, Yanushevich 00 , Minakov DA, Shulgin VA, Kashkarov VM. Early diagnostic of dental caries with the method of laser-induced fluorescence. Russ JDent. 2012;3:47-58.

19. Sarycheva IN, Yanushevich 00 , Minakov DA, Shulgin VA, Kashkarov VM. Laserinduced fluorescence of hard dental tissues. Russ J Dent. 2013;1:17-21.

20. Sarycheva IN, Yanushevich 00, Minakov DA. Fluorescence of enamel in different anatomic areas of intact teeth in vivo. Int JExp Educ. 2013;11:110-1.

21. Sarycheva IN, Yanushevich 00, MinakovDA, Shulgin VA. Influence of dentinenamel junction on the fluorescence of cervical enamel of intact teeth in vivo. Dent Institute. 2013;4:80-81.

22. Sarycheva IN, Yanushevich 00, Minakov DA, Shulgin VA. Influence of enamel thickness on the fluorescence signal of intact teeth in vivo. Russ J Dent. 2014;:1:31-7.

23. Sarycheva IN, Yanushevich 00, Minakov DA, Shulgin VA. Photoluminescence of hard dental tissues. Monograph.Moscow: Publishing house Academy of Natural Science;2014.

24. Arnadottir IB, Saemundsson SR, Holbrook WP.Dental erosion in Icelandic teenagers in relation to dietary and lifestyle factors. Acta Odontol Scand. 2003:61:25-8.Doi:0.1080/ode.61.1.25.28

25. West NX, Maxwell A, Hughes JA, Parker DM, Newcombe RG, Addy M. A method to measure clinical erosion: the effect of orange juice consumption on erosion of enamel. JDent. 1998:26:329-335. Doi:101016/s03005712(97)00025-0.

26. Karan K, Yao X, Xu C, Wang Y.Chemical profile of the dentin substrate in non-carious cervical lesions. Dent Mater. 2009 0ct;25(10):1205-12. doi:10.1016/j. dental.2009.04.006 
27. XuC, Karan K, Yao X, Wang Y. Molecular structural analysis of noncarious cervical sclerotic dentin using Raman spectroscopy.J Raman Spectrosc. 2009;40(12):1780-5.

28. Borisova EG, Uzunov TT,Avramov LA.Early differentiation between caries and tooth demineralization using laser-induced autofluorescence spectroscopy. LasersSurg Med. 2004;34:249-53.Doi: 10.1002/lsm.20009.

29. Vasiliev AYu, Vorobiov Yul, Truten VP.Beam diagnostics in dentistry. Moscow: Publising house Medica; 2007.

30. Pasler FA, Visser H. Radiology practice dentist (in Russian). Moscow: Publishing house MEDpress-Inform;2007.
31. Algazinov EK, Druchenko MA, Sirota AA, Minakov DA, Shulgin VA. Methods of measuring the spectral characteristics and identifying the components of grain mixtures in real-time separation systems.Measurement Techniques.2014;:1:36-41.

32. Algazinov EK, Druchenko MA, Sirota AA, Minakov DA, Shulgin VA. Hardwaresoftware complex for the analysis of a nonuniform flow of objects in real-time optical sorting systems. Measurement Techniques. 2014;5:23-9.

33. Algazinov EK, Druchenko MA, Sirota AA, Minakov DA, Shulgin VA. Methods pattern recognition elements of cereal mixes of results spectral characteristics in the separation system real time. Proceedings of Voronezh State University. Series: System analysis and information technologies. 2013;2:9-19.

Iraida Sarycheva

(Corresponding address)

Address: 10 Studencheskaya Str., Voronezh, Russia

Date submitted: 2019 Sep 24

E-mail:iraidaa@mail.ru

Accept submission: 2020 Jan 07 